\title{
Determinants of the cat bond spread at issuance
}

\author{
Alexander Braun
}

Published online: 4 October 2012

(C) Springer-Verlag Berlin Heidelberg 2012

\begin{abstract}
The contribution at hand is a short summary of a working paper presented by Alexander Braun at the annual meeting of the German Insurance Science Association (DVfVW) in Hannover in March 2012. This working paper contains empirical evidence from the primary market for cat bonds, which provides new insights concerning the prevailing pricing practice of these instruments. For this purpose, transactional information from a multitude of sources has been collected and cross-checked in order to compile a data set comprising virtually all cat bond tranches that were issued between 1997 and 2011. In order to identify the main determinants of the cat bond spread at issuance, a series of OLS regressions with robust standard errors is run. The respective results indicate that, apart from the expected loss, the covered territory, the sponsor, the reinsurance cycle, and the spreads on comparably rated corporate bonds exhibit a significant impact. Based on these findings, a multifactor pricing model for cat bonds in the primary market is then proposed. This model is applicable across all considered territories and perils, exhibits a stable fit with regard to different subsamples used for calibration, and achieves a higher in-sample and outof-sample accuracy than several competing specifications that have been introduced in earlier work.
\end{abstract}

Zusammenfassung Der vorliegende Beitrag stellt eine kurze Zusammenfassung eines Arbeitspapiers dar, das von Alexander Braun im März 2012 auf der Jahrestagung des Deutschen Vereins für Versicherungswissenschaft e. V. (DVfVW) in Hannover präsentiert wurde. Dieses Arbeitspapier beinhaltet empirische Evidenz aus dem Pri-

This contribution summarizes a presentation of a working paper given by the author at the annual meeting of the German Insurance Science Association (DVfVW) in Hannover in March 2012. The full working paper (see Braun, 2011), including all tables and figures, can be found at www.ivw.unisg.ch.

A. Braun $(\bowtie)$

Institute of Insurance Economics, University of St. Gallen, St. Gallen, Switzerland

e-mail: alexander.braun@unisg.ch 
märmarkt für Katastrophenanleihen, die neue Erkenntnisse in Bezug auf die gängige Bewertungspraxis dieser Instrumente liefert. $\mathrm{Zu}$ diesem Zweck wurden transaktionsspezifische Informationen aus einer Vielzahl von Quellen zusammengetragen und abgeglichen, um einen Datensatz zu generieren, der praktisch alle zwischen 1997 und 2011 emittierten Katastrophenanleihentranchen umfasst. Um die wesentlichen Determinanten der Risikoaufschläge von Katastrophenanleihen zum Zeitpunkt der Emission zu identifizieren, wird eine Serie von OLS-Regressionen mit robusten Standardfehlern durchgeführt. Die entsprechenden Ergebnisse zeigen, dass, abgesehen vom erwarteten Verlust, die abgedeckte Region, der Sponsor, der Rückversicherungszyklus sowie die Risikoaufschläge vergleichbar gerateter Unternehmensanleihen einen signifikanten Einfluss ausüben. Auf Grundlage dieser Erkenntnisse wird sodann ein Multifaktor-Bewertungsmodell für Katastrophenanleihen im Primärmarkt vorgeschlagen. Dieses Modell ist über alle betrachteten Regionen und Katastrophenrisiken hinweg anwendbar, weist hinsichtlich verschiedener zur Kalibrierung herangezogener Teilstichproben eine stabile Anpassungsgüte auf und erreicht eine höhere in- und out-of-sample Genauigkeit als etliche konkurrierende Spezifikationen, die in früheren Arbeiten vorgeschlagen wurden.

\section{Introduction}

Throughout the last decade, the market for catastrophe (cat) bonds has witnessed substantial growth rates. Cat bonds are securities that pay regular coupons to investors unless a predetermined event occurs, leading to full or partial loss of capital. The principal is held by a special purpose vehicle (SPV) in the form of highly rated collateral and paid out to the hedging (re)insurer to cover its losses if the trigger condition, as defined in the bond indenture, has been met (see, e.g., Braun 2011). The success of this type of insurance-linked security (ILS) is based on its popularity as an alternative risk transfer technique for (re)insurance companies and on its reputation for exhibiting an appealing risk-return profile as well as a low correlation with traditional asset classes. Particularly institutional fixed-income investors are increasingly attracted by the instrument, since it is fully collateralized and offers an almost pure exposure to natural disaster risk in a familiar bond format (see Swiss Re 2006). Although the cat bond asset class has withstood the major dislocations during the recent financial crisis fairly well, issuance volumes declined sharply in 2008. In the meantime, however, the size of the primary market has returned to precrisis levels. While, compared to other securitizations such as asset-backed securities (ABS), cat bonds still represent a niche segment of the global capital markets, they are starting to reach a critical scale relative to property-catastrophe reinsurance (see Cummins 2008). Thus, it is safe to state that today these instruments have firmly established themselves as a permanent alternative in the risk transfer domain. In addition, academics and practitioners agree that, due to the securitization of new risk types, an increasingly liquid secondary market, and an ever expanding investor base, the future perspectives of the cat bond look bright (see, e.g., Cummins and Weiss 2009; Deutsche Bank 2010).

Despite their growing importance, however, a relatively limited amount of scholarly research has been devoted to the valuation of cat bonds so far. Most extant 
work in this regard is concerned with the development of models based on option pricing theory. In an early article, Loubergé et al. (1999) apply the classical Black and Scholes (1973) assumptions to cat bonds before turning to a compound Poisson process in combination with a simple binomial interest rate model. Another optiontheoretic model for cat bonds built upon a compound Poisson process is presented by Baryshnikov et al. (2001). Lee and Yu (2002) additionally contemplate default risk, moral hazard, and basis risk in a structural credit model with stochastic interest rates as in Cox et al. (1985). Similarly, Vaugirard (2003a, 2003b, 2004) assumes that interest rates adhere to a Vasicek (1977) model and introduces a barrier option framework for cat bonds, relying on a jump-diffusion process for the underlying physical index. Furthermore, Burnecki and Kukla (2003) employ a compound doubly stochastic Poisson process (Cox process) to value zero-coupon and coupon cat bonds. Differentiating between reported losses and incurred but not reported losses, Pérez-Fructuoso (2008) develops a continuous-time model for the underlying of cat bonds with index triggers. Moreover, Reshetar (2008) considers the risk-neutral pricing of insurancelinked securities that combine both natural disaster and extreme mortality risk, Härdle and López Cabrera (2010) examine the calibration of a cat bond for Mexican earthquakes, and Hainaut (2010) derives a method to value cat bonds whose claim arrival process is subject to stochastic seasonality. The approach of Wu and Chung (2010) for the pricing of catastrophe bonds, futures, and options is based on a doubly stochastic Poisson process, while additionally incorporating stochastic interest rates and counterparty default risk, represented by a Cox et al. (1985) and a Jarrow and Yu (2001) model, respectively. Finally, Jarrow (2010) draws on reduced-form modeling methodology from the credit derivatives markets to develop an arbitrage-free closed-form solution for the price of a cat bond.

Another strand of the cat bond pricing literature acknowledges that insurance markets are generally incomplete, implying that it is not possible to replicate all contingent claims with available financial instruments. Consequently, even if arbitrage opportunities are ruled out, a single unique equivalent martingale measure does not exist (see, e.g., Harrison and Kreps 1979). To overcome this problem, these authors resort to equilibrium theory. Cox and Pedersen (2000), for example, derive an approach for cat bond valuation in an incomplete markets setting, employing time separable utility. Moreover, Froot and Posner, Froot and Posner (2000, 2002) develop an equilibrium model for the pricing of multiple event risks under parameter uncertainty. In contrast to that, Young (2004) computes indifference prices for cat bonds based on exponential utility investor preferences, and Egami and Young (2008) extend her work to tranched deals. An incomplete markets approach is also adopted by Zimbidis et al. (2007), who analyze cat bonds for Greek earthquake risk with dynamic interest rates. In addition, Dieckmann (2011) proposes a consumption-based model for cat bonds with an external habit process as in Campbell and Cochrane (1999). Finally, Zhu (2011) explains stylized facts with regard to the cat bond spread by means of an intertemporal equilibrium framework.

Although the aforementioned modeling-oriented literature on catastrophe bonds is growing continuously, it seems that, due to the scarcity of publicly available data, there is a persisting lack of applied research in the area of ILS. One of the few available empirical studies is authored by Lane (2000), who fits a power function with 
two parameters, the probability of first loss and the conditional expected loss, to a small sample of cat bonds from 1999. Lane and Mahul (2008), in contrast, assume a linear relationship between the expected loss and the cat bond spread. Examining primary market data for about 250 cat bond tranches that have been issued between 1997 and early 2008, they illustrate the impact of the underlying peril and the reinsurance cycle. Subsequently, they estimate their model with small cross sections of indicative secondary market prices at two different points in time: the second quarter of 2006 and the first quarter of 2008. Similarly, Dieckmann (2009) considers secondary market data for a cross section of 61 deals before and after the occurrence of Hurricane Katrina in August 2005, aiming to identify significant spread drivers as well as the effect of mega-events on the pricing relation. The impact of the 2005 hurricane season on cat bond spreads is also examined by Ahrens et al. (2009), who draw on the treed Bayesian estimation technique to test the model of Lane (2000) based on 199 observations that were collected between March 2003 and July 2008. Furthermore, Gatumel and Guégan (2009) aggregate market maker quotes for a few cat bond tranches into an index time series, which they employ to study the spread behavior in the secondary market from January 2004 to April 2009. Apart from that, they fit three pricing models to their data and assess the evolution of the respective parameters over time. Another analysis of the primary market is provided by Papachristou (2009), who explores factors that affect the cat risk premium by applying a generalized additive model to 192 bonds launched between January 2003 and July 2008. Moreover, Bodoff and Gan (2009) rely on a sample of 115 transactions issued before 2008 to devise a tractable pricing approach for cat bonds in the primary market, incorporating expected loss, covered territory, and reference peril. Finally, Jaeger et al. (2010) and Galeotti et al. (forthcoming) compare the fit of different models that have been brought forward in the literature. In doing so, the former adopt both cat bond and industry loss warranty (ILW) prices as of August 31, 2009, while the latter use primary market spreads for 176 cat bond transactions between 1999 and 2009 .

Unfortunately, some of these earlier empirical studies appear to suffer from certain shortcomings, such as inconsistent standard errors, small sample sizes, and selection bias. Bodoff and Gan (2009), for example, completely exclude multiperil transactions from their analysis, and Galeotti et al. (forthcoming) solely incorporate Standard \& Poor's (S\&P) rated cat bonds. In addition, despite a rather strong data basis and the introduction of the peril and the reinsurance cycle as new explanatory variables, Lane and Mahul (2008) see their work as a preliminary effort and encourage more extensive empirical research in the future. Accordingly, it is safe to state that, apart from the expected loss, other determinants of the cat bond spread are still not sufficiently well understood. Moreover, most authors do not propose and benchmark an own pricing model. The paper at hand is intended to address some of these issues by contributing new empirical evidence from the primary market. For this purpose, we have compiled the most comprehensive data set of cat bond deals considered in the literature to date, comprising virtually all tranches that were issued in the 14 years between June 1997 and August 2011. Hence, our analysis is going to account for every important event since the inception of this market in the 1990s, such as its takeoff period, the major shock due to Hurricane Katrina in 2005, as well as the global financial crisis in 2008 and 2009. From our data set, we create a large sample of over 350 bonds and run a 
series of ordinary least squares (OLS) regressions with heteroskedasticity consistent standard errors to identify the main drivers of the cat bond spread at the time of issuance. Based on these findings, we then propose a multifactor pricing model for cat bonds in the primary market and assess its in-sample and out-of-sample performance relative to other approaches that have been suggested in the literature.

The remainder of this summary is organized as follows. In Sect. 2, we review the typical characteristics of cat bond transactions, such as the structure, the trigger types, and the underlying perils, and derive a range of testable hypotheses. Furthermore, Sect. 3 contains a description of our data set, the statistical methodology, as well as the approach that has been employed to identify outliers and generate the final sample. A brief overview of our empirical analysis of pricing in the primary market for cat bonds as well as the comparison of the different factor models is provided in Sects. 4 and 5. Finally, in Sect. 6 we draw our conclusion.

\section{Background and development of hypotheses}

\subsection{Catastrophe bonds}

A solid understanding of the general mechanics of cat bonds is crucial for the evaluation of the empirical results in the following sections. Therefore, we will provide a brief introduction to this financial instrument below. Cat bonds have been developed by insurers and reinsurers as a means to transfer natural disaster risks to the capital markets. As depicted in Fig. 1, at the heart of a typical transaction is an SPV that sells protection against catastrophe losses to the sponsoring company via a reinsurance contract (or a cat swap). ${ }^{1}$ To fund the risk incurred thereby, the SPV issues securities to investors and uses the proceeds to purchase collateral, which is then held in a trust account. In case a catastrophic event occurs before maturity (or during a predefined risk period) and triggers the embedded reinsurance contract, the collateral is liquidated to reimburse the sponsor, and investors lose all or part of their principal. ${ }^{2}$ For bearing this risk they are compensated with regular coupons, consisting of a variable interest rate (e.g., LIBOR) plus a spread that we denote $S^{\text {CAT }}$. This spread reflects the price of a cat bond and consists of the expected loss of the tranche plus a risk premium. ${ }^{3}$

Furthermore, until late 2008, it was common to protect the structure against interest rate risk and collateral impairment through a total return swap (TRS). In exchange for the fixed coupons and value gains of the collateral, the swap counterparty provided a floating rate payment plus the TRS spread $\left(S^{\mathrm{TRS}}\right)$ and covered all collateral losses. However, the default of the investment bank Lehman Brothers, which acted as swap counterparty in four cat bond deals, revealed that the combination of TRS and

\footnotetext{
${ }^{1}$ For a comprehensive discussion of cat swap contracts refer to Braun (2011).

${ }^{2}$ Note that both binary and proportional payouts to the sponsor are possible (see, e.g., Cummins and Weiss 2009).

${ }^{3}$ This is the same logic as for corporate bond spreads (see, e.g., Elton et al. 2001).
} 


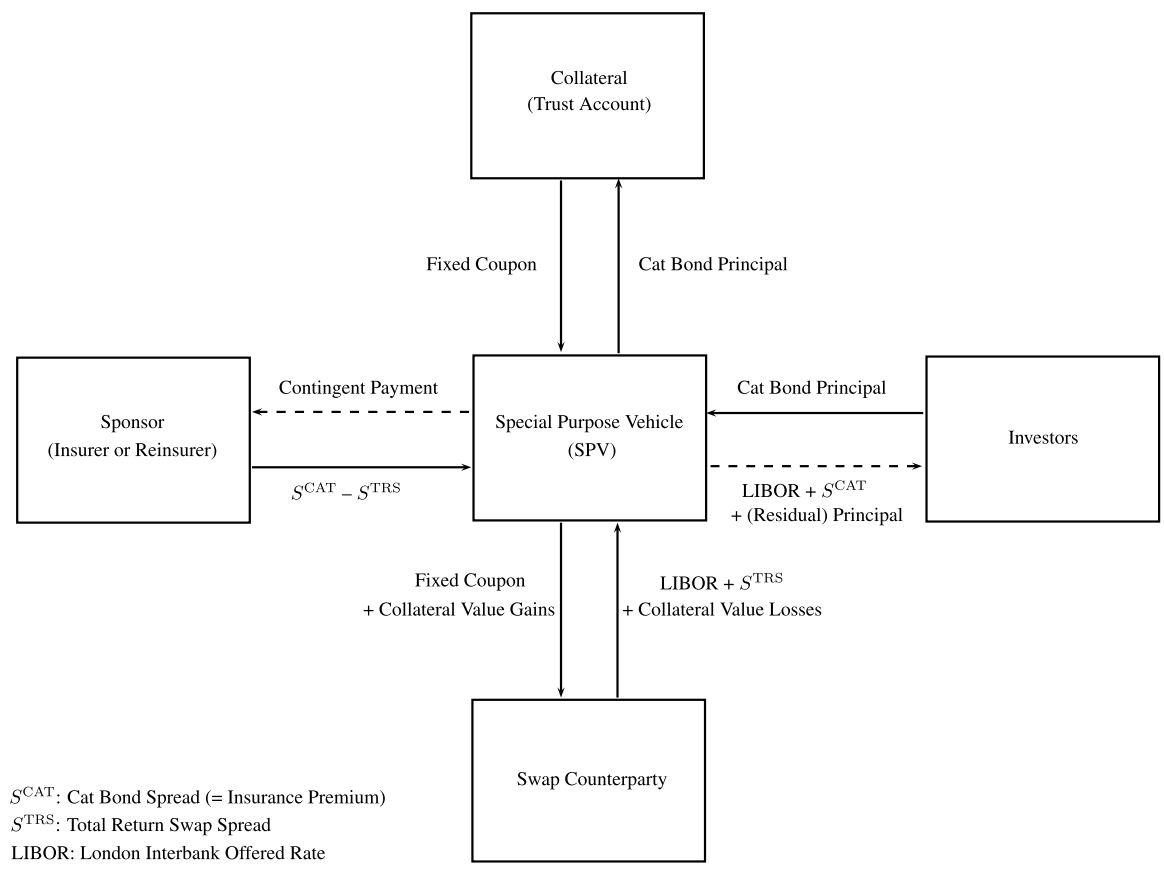

Fig. 1 Typical structure of a cat bond transaction

inadequate collateral assets (in terms of both credit quality and maturity) is associated with a nonnegligible degree of credit risk (see, e.g., Cummins and Weiss 2009). ${ }^{4}$ Hence, newer issues either rely on much tighter collateral arrangements, including strict criteria for permissible investments, increased monitoring requirements, and top-up provisions, or they refrain from utilizing a TRS altogether (see, e.g., Towers Watson 2010). Another relatively recent development in the cat bond market is the increasing usage of shelf-offerings such as the Swiss Re Successor Series (see, e.g., Guy Carpenter 2008). These programs enable sponsors, within a certain time span and up to a maximum volume, to repeatedly issue additional classes of notes (referred to as "takedowns") out of the same SPV and based on a single offering circular that covers the general characteristics of the securities. In doing so, it is possible to access risk bearing capacity as needed and achieve a substantial reduction in transaction costs. Moreover, shelf offering programs tend to be welcomed by investors since they indicate the experience of a sponsor as well as its willingness to provide a steady deal flow in the future (see, e.g., Spry 2009).

In order to determine whether a payout to the cat bond sponsor is due, different types of triggers can be applied. ${ }^{5}$ Each of these mechanisms is based on a preset threshold value that needs to be breached by a certain underlying measure. The choice of trigger typically involves a trade-off between transparency and basis risk (see, e.g.,

\footnotetext{
${ }^{4}$ The affected transactions were Ajax Re, Carillon Ltd. A-1, Newton Re 2008 A-1, and Willow Re B.

${ }^{5}$ See Hagedorn et al. (2009) for a more detailed discussion of the choice of trigger types.
} 
Swiss Re 2009). Indemnity triggers are associated with asymmetric information between the transaction partners, since they directly reference the losses incurred by the sponsor. Consequently, they give rise to a moral hazard problem. More specifically, due to the acquired protection, the sponsor of an indemnity-based cat bond has the incentive to relax its underwriting and claims handling standards to the detriment of the investors. Furthermore, the payout of transactions with indemnity triggers needs to be preceded by a rather lengthy loss verification process, implying that a quick settlement after the occurrence of a qualifying event is not possible. While non-indemnity triggers can be employed to tackle these issues, they expose the sponsor to basis risk since the actual losses in its portfolio of insurance contracts are, in general, not perfectly correlated with the measure referenced by the trigger. A quite prominent non-indemnity trigger is the industry index trigger, which is based on the losses of the whole insurance sector. The respective claims data is collected and aggregated by third-party service providers such as Property Claims Services (PCS). Furthermore, modeled loss triggers require the physical parameters of the disaster to be entered into an escrow model that serves to determine the relevant losses. In contrast to that, pure parametric triggers focus on the physically measured severity of the catastrophe instead of claim sizes. ${ }^{6}$ Besides, there is a refined version of the pure parametric trigger called parametric index trigger. Here, physical parameters are aggregated into an index, the value of which then determines whether the sponsor receives a payment. Finally, cat bonds can also feature a combination of multiple trigger types.

The actual natural hazard risk securitized by cat bonds is specified by a combination of covered territory and reference peril (see, e.g., Jaeger et al. 2010). ${ }^{7}$ The covered territory represents the geographic area in which a catastrophic event has to occur in order to be relevant under the bond indenture and is commonly defined in terms of countries (e.g., United States), regions (e.g., Gulf Coast), or states (e.g., California). Reference peril, in contrast, means the underlying type of disaster, such as windstorms (e.g., hurricanes, tornadoes, typhoons) or earthquakes. Today, the most widespread combinations of covered territory and reference peril are U.S. Wind, U.S. Earthquake, Europe Wind, and Japan Earthquake (see, e.g., AON Benfield 2011). In addition, cat bonds referencing multiple territories and multiple perils have become quite common (see, e.g., Swiss Re 2009). ${ }^{8}$

These stringent definitions are necessary to ensure that the occurrence of a qualifying event can be determined objectively. In addition, they are a crucial input for analytics firms such as RMS, AIR, and EQECAT, which assume a central role in the quantification of the catastrophe risk. ${ }^{9}$ For this purpose, they maintain complex scientific models to simulate stochastic event sets, i.e., large numbers of disaster scenarios that are characterized by key physical parameters such as wind speeds or tremor

\footnotetext{
${ }^{6}$ In this context, one commonly draws on the Richter Scale for earthquakes and the Saffir-Simpson Scale for hurricanes.

${ }^{7}$ Note that, in practice, the term "peril" is frequently used to refer to the actual combination of geographic zone and natural hazard (see, e.g., Bodoff and Gan 2009). Hence, the terminology in this regard is not entirely precise.

${ }^{8}$ Lane (2004) establishes a relationship between multiperil and singleperil cat bonds based on no-arbitrage considerations.

${ }^{9}$ A detailed description of the catastrophe modeling process can be found in Brookes (2009).
} 
magnitudes as well as the corresponding occurrence probabilities. These scenarios are then superimposed on large databases containing all properties that, due to their locations, are exposed to the respective catastrophe risk. ${ }^{10}$ Together with information about the damage susceptibility of each structure, as determined by the main construction materials, the age, the size, etc., it is thus possible to estimate the physical damage taken by buildings and household belongings in every scenario. Finally, based on the property values as well as the terms of active insurance policies, the expected damage is translated into financial and insured losses and aggregated on the portfolio level. In combination with the trigger parameters of a cat bond issue, the data output generated by this probabilistic analysis enables the modeling firms to derive a loss distribution for each tranche. This distribution underlies the derivation of key risk metrics, such as the probability of first loss, the expected loss, as well as the probability of exhaustion, and is therefore central to the risk assessment of cat bonds. Consequently, it is also one of the main aspects that drive the rating of a transaction. However, apart from the likelihood of a loss due to the underlying disaster risk, rating agencies also consider the default risk of the sponsor, the collateral assets, and a potential swap counterparty (see, e.g., Heath 2009). ${ }^{11}$

\subsection{Testable hypotheses}

Due to the similarities of ILS with traditional reinsurance contracts, the expected loss has emerged as the main measure for the riskiness of such transactions. Consequently, it is also considered to be the single most important driver of the cat bond spread. Since empirical evidence for this notion has already been provided in several earlier studies (see, e.g., Lane and Mahul 2008; Dieckmann 2009; Galeotti et al. forthcoming), we do not see the necessity of formulating an explicit hypothesis in this regard. Instead, our attention is focused on other potential spread determinants that could help to increase the explanatory power of a factor pricing model for cat bonds at the time of issuance.

First of all, we consider the bond-specific characteristics issue size, tenor (time to maturity), and trigger type. In line with Dieckmann (2009), we base our presumption concerning the first of these three variables on the findings of Edwards et al. (2007) for the corporate bond market, who show that larger issue volumes are associated with lower transaction costs, which, in turn, lead to a higher liquidity and ultimately lower required yields to maturity. Moreover, if the expectations, the liquidity preference, or the market segmentation hypotheses hold, the cat bond spread should be somehow dependent on the tenor of the security. ${ }^{12}$ Finally, due to the longer post-event loss verification process and the possibility of moral hazard by the sponsor, it is likely

\footnotetext{
${ }^{10}$ The identification of relevant structures is supported by the process of geocoding, which serves to convert address information into geographic coordinates, consisting of latitude and longitude (see, e.g., Brookes 2009).

${ }^{11}$ Rating agencies commonly adopt a "weak-link approach" for cat bonds. Further information with regard to the corresponding methodology can be found in Standard and Poor's (2009), Moody's (2006), and Fitch Ratings (2011).

${ }^{12}$ These strands of thought underpin common theories of the term structure of interest rates (see, e.g., Cox et al. 1985)
} 
that investors will demand to be compensated with higher spreads in case a cat bond exhibits an indemnity trigger. Taking these considerations into account, we formulate the following three hypotheses:

$H_{1}(a)$ : The spread of a cat bond issue decreases with its size.

$H_{1}(b)$ : Cat bond spreads differ according to the tenor of the security.

$H_{1}(c):$ A pure indemnity trigger is associated with a markup in the cat bond spread.

Second, we turn to the variables covered territory and reference peril, which characterize the catastrophe risk underlying each transaction. A potential peril-specific impact on the cat bond spread has already been documented by Bodoff and Gan (2009) and was subsequently controlled for in later studies (see, e.g., Galeotti et al. forthcoming). ${ }^{13}$ We will additionally provide for a strict differentiation between the geographic scope and the type of disaster. With regard to the former, Papachristou (2009) claims it is a matter of common knowledge among market participants that cat bonds covering the U.S. carry larger spreads than transactions exposing investors to similar natural hazards in the rest of the world. This phenomenon is attributed to the fact that the vast majority of outstanding risk capital in the cat bond market relates to events on U.S. soil, thus characterizing the country as a peak territory. Transactions covering nonpeak zones, in contrast, are a sought-after means for the diversification of cat bond portfolios. Consequently, they should exhibit lower risk loads. Furthermore, due to the differences in scientific models for the main types of disasters, the density and values of the properties in the typical exposed areas, as well as the perceived uncertainty in the estimated loss distributions, one could expect cat bond spreads to vary by reference peril. Apart from these separate effects, there might be a combined impact of covered territory and reference peril as well, since, in practice, these two factors are commonly considered together (see previous section). Based on these thoughts, we postulate:

$\mathrm{H}_{2}(\mathrm{a}):$ The cat bond spread is higher for peak territories than for nonpeak territories.

\section{$\mathrm{H}_{2}(\mathrm{~b})$ : Cat bond spreads vary by reference peril.}

\section{$\mathrm{H}_{2}(\mathrm{c})$ : Specific combinations of covered territory and reference peril affect the cat bond spread.}

A third batch of potential explanatory factors above and beyond the expected loss relates to reinsurance pricing and the investors' perception of credit risk inherent in cat bond structures. Spry (2009) notes that when deciding on their required spreads, committed cat bond investors also assess the specifics of the sponsor. Therefore, repeat issuers with a strong track record can expect to be rewarded with tighter execution pricing (see, e.g., Guy Carpenter 2008). In addition, Lane and Mahul (2008) were the first to point out the relevance of the underwriting cycle with regard to cat

${ }^{13}$ Lane and Mahul (2008) examine the impact of peril-specific expected loss on the spread of multiperil cat bonds. 
bond pricing. Researchers and industry experts agree that the reinsurance business is subject to periods of soft markets with plenty of coverage and rather low premiums as well as hard markets with restricted risk-bearing capacities and higher premiums (see, e.g., Cummins and Weiss 2009). Thus, being a direct substitute for traditional reinsurance contracts, cat bonds should, by no-arbitrage reasoning, follow relatively similar pricing patterns over time. Moreover, it is a matter of common knowledge that yields for corporate and government bonds vary across rating classes (see, e.g., Elton et al. 2001). A similar link can be suspected between the spread of a cat bond and its rating. Finally, since many fixed-income investors perceive securities with the same rating to carry identical risks, there could be contagion effects that give rise to a dependence of cat bond on corporate bond spreads. The fact that, due to the collateral, the sponsor, and a potential TRS counterparty, cat bond structures always hide a residual degree of credit risk further contributes to this view. To sum up, we state our last hypotheses as follows:

$\mathrm{H}_{3}($ a): Long-standing and well-respected sponsors can afford to pay lower cat bond spreads.

$H_{3}(b)$ : Cat bond spreads fluctuate in line with the reinsurance underwriting cycle.

$H_{3}(c)$ : The higher the rating class of a cat bond, the lower its spread.

$H_{3}(d)$ : Corporate bond spreads exert a positive influence on cat bond spreads.

\section{Data, methodology, and elimination of outliers}

The biggest obstacle for empirical work on cat bonds is the scarcity of publicly available transaction data. To tackle this problem, we needed to combine and cross-check information from a multitude of different sources, including the Thomson Reuters Insurance Linked Securities Community, trade notes by Lane Financial LLC, the Artemis Deal Directory, rating agency reports, as well as market research of Swiss Re, Munich Re, Aon Benfield, and Guy Carpenter. The resulting data set comprises a total of 402 cat bond tranches that have been issued between June 1997 and August 2011. In addition to the cat bond spread and key risk metrics, such as the expected loss, the probability of first loss, and the conditional expected loss, we were able to acquire information about the issue date, issue size, tenor, trigger type, covered territory, reference peril, sponsor, and rating of almost every bond. ${ }^{14}$ Nevertheless, 33 deals needed to be removed again due to missing fields. Apart from transactional aspects, our hypotheses also comprise the environmental factors "underwriting cycle" and "corporate bond spreads". We proxy the former by means of the Lane Financial LLC Synthetic Rate on Line Index, which is published by the Thomson Reuters Insurance Linked Securities Community on a quarterly basis. Since pricing information for traditional reinsurance contracts is rather opaque and difficult to obtain, this index

\footnotetext{
${ }^{14}$ Unfortunately further details, such as the employed cat modeling firm, the lead underwriters, and the TRS counterparty, were only sporadically available.
} 


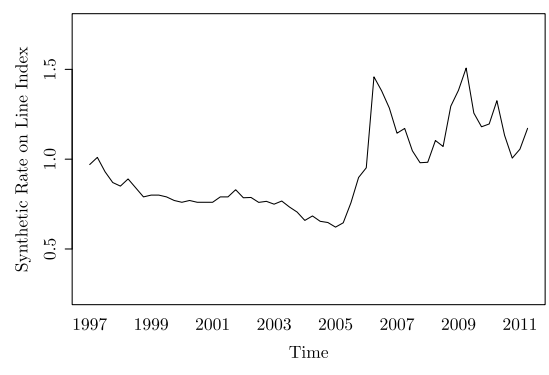

(a) Synthetic Rate on Line Index

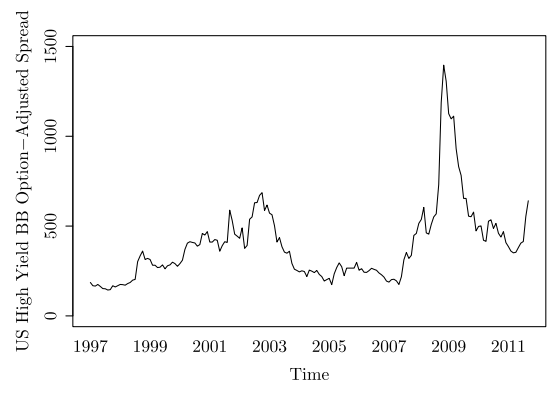

(b) US High Yield BB Option-Adjusted Spread

Fig. 2 Potential cyclical drivers of the cat bond spread

draws on secondary market quotes for all outstanding ILS as well as ILW premiums to measure shifts in catastrophe risk prices. ${ }^{15}$ Furthermore, due to the fact that the vast majority of cat bonds exhibit a BB rating, we decide to capture the influence of the corporate bond markets via the Bank of America Merrill Lynch US High Yield BB Option-Adjusted Spread (measured in basis points), which is available on a monthly basis. Figure 2 shows the development of these potential cyclical drivers of the cat bond spread between 1997 and 2011.

Our analysis will rely on OLS estimation methodology. The linear functional form has already been shown to be an adequate choice for the prediction of cat bond spreads in earlier work on the subject (see, e.g., Galeotti et al. forthcoming). The standard linear regression model for $N$ cross-sectional data points and $k$ independent variables (including an intercept) can be described as

$$
\mathbf{y}=\mathbf{X} \boldsymbol{\beta}+\boldsymbol{\epsilon},
$$

where $\mathbf{y}=\left(y_{1}, \ldots, y_{N}\right)^{\prime}$ denotes the $N \times 1$ vector of values of the dependent variable, $\mathbf{X}=\left(\mathbf{x}_{1}^{\prime}, \ldots, \mathbf{x}_{N}^{\prime}\right)^{\prime}$ is an $N \times k$ matrix whose column vectors include the values for the explanatory variables (regressors), $\boldsymbol{\beta}=\left(\beta_{1}, \ldots, \beta_{k}\right)^{\prime}$ represents the $k \times 1$ vector of unknown regression coefficients, and $\epsilon=\left(\epsilon_{1}, \ldots, \epsilon_{N}\right)^{\prime}$ stands for the $N \times 1$ random vector of independent and identically distributed (iid) errors (disturbances), which captures all effects on $\mathbf{y}$ that are not caused by the $\mathbf{X}$. The OLS estimator of $\boldsymbol{\beta}$ is defined as follows (see, e.g., White 1980):

$$
\hat{\boldsymbol{\beta}}=\left(\mathbf{X}^{\prime} \mathbf{X}\right)^{-1} \mathbf{X}^{\prime} \mathbf{y} .
$$

It minimizes the sum of squared residuals implied by the model and can be computed from a random sample $\left\{\left(y_{i}, x_{i 1}, \ldots, x_{i k}\right): i=1, \ldots, N\right\}$ of $N$ observations for

\footnotetext{
${ }^{15}$ Please refer to the Thomson Reuters Insurance Linked Securities Community for additional information about this index, including the current calculation methodology. Since the time series available online does not date back to before 2002, we have combined it with earlier data of the long-term index of catastrophe reinsurance prices, which is based on a similar calculation methodology and has been published by Lane and Mahul (2008) in an appendix to their article. The adequacy of this approach is underlined by the fact that both indices are highly correlated during the time period between the first quarters of 2002 and 2008, in which they overlap. The resulting time series is set to start with a value of one in the fourth quarter of 1996.
} 
the dependent variable and the regressors (see, e.g., Wooldridge 2008). The corresponding fitted residuals are given by

$$
\mathbf{e}=\mathbf{y}-\hat{\mathbf{y}}=\mathbf{y}-\mathbf{X} \hat{\boldsymbol{\beta}},
$$

with $\mathbf{e}=\left(e_{1}, \ldots, e_{N}\right)^{\prime}$. Moreover, $\hat{\mathbf{y}}=\mathbf{X} \hat{\boldsymbol{\beta}}=\left(\hat{y}_{1}, \ldots, \hat{y}_{N}\right)^{\prime}$ are the fitted values, i.e., the model's predictions for the dependent variable based on the observed values for $\mathbf{X}$. The unbiasedness and efficiency of the OLS estimator critically hinges on the Gauss-Markov assumptions, which state that (i) the linear functional form is the correct specification for the population model, (ii) the observations have been randomly sampled, (iii) there are no perfect linear relationships among the regressors (no multicollinearity), (iv) the error has a zero mean conditional on the values of the regressors $(\mathrm{E}[\boldsymbol{\epsilon} \mid \mathbf{X}]=0)$, and (v) the error is homoskedastic, implying that it exhibits the same variance given any values of the regressors $\left(\operatorname{Var}[\boldsymbol{\epsilon} \mid \mathbf{X}]=\sigma^{2}\right)$. As long as these five conditions hold, $\hat{\boldsymbol{\beta}}$ is the best linear unbiased estimator (BLUE). ${ }^{16}$

Finally, before running our empirical analysis, we also want to identify outliers, i.e., cases with an abnormally large impact on the OLS estimators of the regression coefficients. To this end, we follow a systematic process based on clear-cut statistical criteria. ${ }^{17}$ First of all, we estimate a model with all potential regressors and save the fitted residuals $e_{i}(i=1, \ldots, N) .{ }^{18}$ Subsequently, we compute the (internally) studentized residuals, which are defined as

$$
e_{i}^{S}=\frac{e_{i}}{S E E \sqrt{1-h_{i i}}}, \quad i=1, \ldots, N,
$$

where $S E E=\sqrt{\mathbf{e}^{\prime} \mathbf{e} /(N-k)}$ is the standard error of the estimate and $h_{i i}$ equals the distance of case $i$ from the centroid of a scatter plot of the $e_{i}$ against the $\hat{y}_{i}$. The $h_{i i}$ can be found on the main diagonal of the $N \times N$ matrix $\mathbf{H}=\mathbf{X}\left(\mathbf{X}^{\prime} \mathbf{X}\right)^{-1} \mathbf{X}^{\prime}$. Moreover, using the $e_{i}^{s}$, we obtain the externally studentized (jackknifed) residuals as follows:

$$
t_{i}=\frac{e_{i}}{S E E_{-i} \sqrt{1-h_{i i}}}=e_{i}^{s} \sqrt{\frac{N-k-1}{N-k-\left(e_{i}^{s}\right)^{2}}}, \quad i=1, \ldots, N,
$$

with $S E E_{-i}$ being the standard error of the estimate when the i-th case has been removed from the sample. Hence, in order to obtain the $S E E_{-i}$ and, in turn, the $t_{i}$, one could simply reestimate the model repeatedly, excluding one of the $N$ cases in

\footnotetext{
${ }^{16}$ Sometimes the Gauss-Markov assumptions are extended by additionally requiring the errors to be normally distributed with mean zero and constant variance $\sigma^{2}$, i.e., $\epsilon \sim \mathrm{N}\left(0, \sigma^{2}\right)$. This complementary condition, which constitutes the classical linear model assumptions, is negligible for large enough sample sizes, since, in those cases, the central limit theorem provides for asymptotic normality (see, e.g., Wooldridge 2008). In addition, one should bear in mind that the errors need to be stochastically independent of each other. Due to the rather rare occurrence of spatial autocorrelation in financial economics, however, this assumption is typically satisfied for cross-sectional analyses. In contrast to that, it represents a common problem when running OLS regressions on time series data.

${ }^{17}$ The following definitions and formulae can, e.g., be found in Kianifard and Swallow (1996).

${ }^{18}$ The complete list of regressors comprises five continuous variables (expected loss, issue size, tenor, synthetic rate on line index, BB corporate bond spread) and nine dummy variables (trigger, wind, earthquake, multiterritory, U.S., Europe, Japan, sponsor, rating). A more detailed description can be found in the full paper by the author (see Braun 2012).
} 


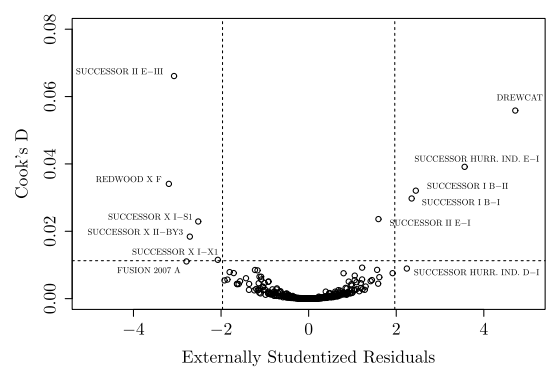

(a) Cook's D vs. Externally Studentized Residuals

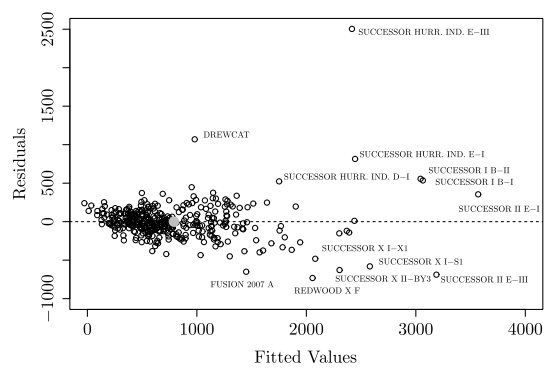

(b) Residuals vs. Fitted Values

Fig. 3 Identification of outliers

each step. An equivalent but less computationally intensive way to arrive at the same result is given by the right-hand side of Eq. (5). Furthermore, the $e_{i}^{s}$ and $h_{i i}$ can also be employed to calculate Cook's D (distance), another commonly used measure for the influence of an observation on the OLS estimators that is given by

$$
D_{i}=\frac{\left(e_{i}^{s}\right)^{2}}{k} \frac{h_{i i}}{1-h_{i i}} .
$$

Since the externally studentized residuals are t-distributed with $N-k=354$ degrees of freedom, we are able to derive a critical value of \pm 1.97 for the 5 percent significance level. Each $t_{i}$ in excess of this threshold indicates an outlier. ${ }^{19}$ Similarly, cases that display a Cook's D in excess of $4 /(N-k)=0.01$ are considered as unusual. A way to visually combine these statistics is shown in Fig. 3(a), in which Cook's D for each case is plotted against the corresponding externally studentized residual. By means of this chart, we are able to reveal the 13 cases outside the box in the bottom center as heavily influential observations. ${ }^{20}$ This finding can be confirmed by examining the scatter plot of the residuals against the fitted values shown in Fig. 3(b), since the previously identified outliers exhibit some of the largest distances to the centroid, i.e., the spot marked by a gray circle around which all other cases cluster. When considering these 13 cat bonds in more detail, we notice that 10 of them belong to the Swiss Re successor series. Hence, this particular shelf offering program seems to adhere to somewhat different pricing rules than the other cat bonds in our data set. After the outliers have been removed, we can begin our analysis with a sample of 356 bonds.

\section{Empirical analysis}

In this section, we firstly draw on our data set to document a number of facts about the primary market for cat bonds, such as the considerable decline of annual new

\footnotetext{
${ }^{19}$ Recall that 33 of the original 402 bonds have already been eliminated due to missing data. Hence, our $N$ for this analysis equals 369 , from which we subtract a total of 14 regressors plus the intercept.

${ }^{20}$ Note: case 183 (Successor Hurricane Ind. Class E-III) is not visible as it lies beyond the outer bounds of Fig. 3(a).
} 
issue volumes after the default of Lehman Brothers in 2008, the subsequent rebound up to almost precrisis levels, and the peaks in the average intra-year issuance activity during the second and the fourth quarter. Apart from that, a clear downward trend in the multiple of spread to expected loss can be observed between 1997 and 2011, although the spreads for cat bonds still seem to remain higher than those for comparably rated corporate debt. Secondly, we provide a variety of descriptive statistics to characterize our sample. Lastly, a series of OLS regressions with heteroskedasticity consistent standard errors is conducted that allow us to identify the main determinants of the primary market cat bond spread. A more detailed discussion of this empirical analysis, including all tables and figures can be found in the full working paper by the author.

\section{Multifactor pricing model}

Based on our findings in Sect. 4, we suggest a multifactor pricing model for cat bonds at the time of issuance, which is applicable across territories and perils. We then assess its stability by reestimating the model on three similarly sized subsamples for different time periods as well as three peril-specific subsamples that exclusively comprise wind, earthquake, or multiperil bonds. Finally, the model's in-sample and out-of-sample accuracy are compared to a number of competing specifications that have been proposed in the extant empirical literature on cat bond pricing. ${ }^{21}$ Again, the reader is referred to Braun (2012) for the complete set of results.

\section{Summary and conclusion}

Our findings indicate that the expected loss, the covered territory, the sponsor, the reinsurance cycle, and the $\mathrm{BB}$ corporate bond spread are major drivers of the cat bond spread. In contrast to that, the issue size, tenor, trigger, and type of peril do not seem to be priced. Hence, we are able to confirm hypotheses 2(a) and 3. Moreover, the multifactor pricing model that we derive from these insights exhibits a stable fit with regard to the different subsamples that are used for calibration and achieves a higher in-sample and out-of-sample accuracy than the alternative specifications that are considered. Due to the scarcity of empirical work in this area, we believe that our results may contribute to a broader understanding of the cat bond asset class and should thus be relevant to investors, sponsors, and risk managers alike. Despite our comprehensive analysis, however, a number of open questions remain. First and foremost, our approach has been specifically designed to price newly issued transactions. Therefore, some of the determinants that have been incorporated in the respective specification are not entirely suitable for a recurring valuation of cat bond portfolios over time. Hence, in future research, one could aim to develop a similarly accurate model for the secondary market. We are convinced that additional empirical evidence is essential to increase the transparency and promote the growth of this still relatively small segment of the capital markets.

${ }^{21}$ An overview of these models can be found in Jaeger et al. (2010). 


\section{References}

Ahrens, F., Fuess, R., Kestel, S.: An econometric pricing model for CAT bonds and the impact of the 2005 hurricane season. Working paper (2009)

AON Benfield: Insurance-linked securities-consistency and confidence 2011. Research report (2011)

Baryshnikov, Y., Mayo, A., Taylor, D.R.: Pricing of CAT bonds. Preprint (2001)

Black, F., Scholes, M.: The pricing of options and corporate liabilities. J. Polit. Econ. 81(3), 637-654 (1973)

Bodoff, N.M., Gan, Y.: An analysis of the market price of cat bonds. In: Casualty Actuarial Society EForum. Spring (2009)

Braun, A.: Pricing catastrophe swaps: a contingent claims approach. Insur. Math. Econ. 49(3), 520-536 (2011)

Braun, A.: Pricing in the primary market for cat bonds: new empirical evidence. Working papers on risk management and insurance (2012)

Brookes, B.: Risk modelling and the role and benefits of cat indices. In: Barrieu, P., Albertini, L. (eds.) The Handbook of Insurance-Linked Securities, 1st edn., pp. 83-100. Wiley, West Sussex (2009). Chap. 7

Burnecki, K., Kukla, G.: Pricing of zero-coupon and coupon CAT bonds. Appl. Math. 30(3), 315-324 (2003)

Campbell, J.Y., Cochrane, J.H.: By force of habit: a consumption-based explanation of aggregate stock market behavior. J. Polit. Econ. 107(2), 205-251 (1999)

Cox, J.C., Ingersoll, J.E. Jr, Ross, S.A.: A theory of the term structure of interest rates. Econometrica 53(2), 385-407 (1985)

Cox, S.H., Pedersen, H.W.: Catastrophe risk bonds. N. Am. Actuar. J. 4(4), 56-82 (2000)

Cummins, J.D.: CAT bonds and other risk-linked securities: state of the market and recent developments. Risk Manag. Insur. Rev. 11(1), 23-47 (2008)

Cummins, J.D., Weiss, M.A.: Convergence of insurance and financial markets: hybrid and securitized risktransfer solutions. J. Risk Insur. 76(3), 493-545 (2009)

Deutsche Bank: Insurance-linked securities-a niche market expanding. Research report (2010)

Dieckmann, S.: By force of nature: explaining the yield spread on catastrophe bonds. Working paper, University of Pennsylvania (2009)

Dieckmann, S.: A consumption-based evaluation of the cat bond market. Working paper, University of Pennsylvania (2011)

Edwards, A.K., Harris, L.E., Piwowar, M.S.: Corporate bond market transaction costs and transparency. J. Finance LXII(3), 1421-1451 (2007)

Egami, M., Young, V.R.: Indifference prices of structured catastrophe (CAT) bonds. Insur. Math. Econ. 42(2), 771-778 (2008)

Elton, E.J., Gruber, M.J., Agrawal, D., Mann, C.: Explaining the rate spread on corporate bonds. J. Finance 56(1), 247-277 (2001)

Fitch Ratings: Insurance-linked securities—sector specific rating criteria. Report (2011)

Froot, K.A., Posner, S.: Issues in the pricing of catastrophe risk. Contingencies (November/December) 68-73 (2000)

Froot, K.A., Posner, S.E.: The pricing of event risks with parameter uncertainty. Geneva Pap. Risk Insur., Theory 27(2), 153-165 (2002)

Galeotti, M., Guertler, M., Winkelvos, C.: Accuracy of premium calculation models for CAT bonds-an empirical analysis. Journal of Risk and Insurance (forthcoming)

Gatumel, M., Guégan, D.: Towards an understanding approach of the insurance-linked securities market. Working paper, University of Paris (Panthéon-Sorbonne) (2009)

Guy Carpenter: The catastrophe bond market at year-end 2007: the market goes mainstream. Report, New York (2008)

Hagedorn, D., Heigl, C., Mueller, A., Seidler, G.: Choice of triggers. In: Barrieu, P., Albertini, L. (eds.) The Handbook of Insurance-Linked Securities, 1st edn., pp. 37-48. Wiley, West Sussex (2009)

Hainaut, D.: Pricing of a catastrophe bond, with a seasonal effect. Working paper (2010)

Härdle, W.K., López Cabrera, B.: Calibrating CAT bonds for Mexican earthquakes. J. Risk Insur. 77(3), 625-650 (2010)

Harrison, J., Kreps, D.: Martingales and arbitrage in multiperiod securities markets. J. Econ. Theory 20(3), 381-408 (1979)

Heath, C.: Rating methodology. In: Barrieu, P., Albertini, L. (eds.) The Handbook of Insurance-Linked Securities, 1st edn., pp. 65-82. Wiley, West Sussex (2009). Chap. 6 
Jaeger, L., Mueller, S., Scherling, S.: Insurance-linked securities: what drives their returns? J. Altern. Invest. 13(2), 9-34 (2010)

Jarrow, R.A.: A simple robust model for cat bond valuation. Finance Res. Lett. 7(2), 72-79 (2010)

Jarrow, R.A., Yu, F.: Counterparty risk and the pricing of defaultable securities. J. Finance 56(5), 17651799 (2001)

Kianifard, F., Swallow, W.H.: A review of the development and application of recursive residuals in linear models. J. Am. Stat. Assoc. 91(433), 391-400 (1996)

Lane, M.N.: Pricing risk transfer transactions. ASTIN Bull. 30(2), 259-293 (2000)

Lane, M.N.: Arbitrage algebra and the price of multi-peril ILS. J. Risk Finance 5(2), 45-51 (2004)

Lane, M.N., Mahul, O.: Catastrophe risk pricing: an empirical analysis. Working paper, The World Bank (2008)

Lee, J.-P., Yu, M.-T.: Pricing default-risky CAT bonds with moral hazard and basis risk. J. Risk Insur. 69(1), 25-44 (2002)

Loubergé, H., Kellezi, E., Gilli, M.: Using catastrophe-linked securities to diversify insurance risk: a financial analysis of CAT bonds. J. Insur. Issues 22(2), 125-146 (1999)

Moody's: Moody's approach to rating new catastrophe bond perils and the securitization of mortality risk. Report (2006)

Papachristou, D.: Statistical analysis of the spreads of catastrophe bonds at the time of issue. Working paper (2009), presented at the 39th ASTIN Colloquium

Pérez-Fructuoso, M.J.: Modeling loss index triggers for CAT bonds: a continuous approach. Variance 2(2), 253-265 (2008)

Reshetar, G.: Pricing of multiple-event coupon paying CAT bond. Working paper, University of Zurich (2008)

Spry, J.: Non-life insurance securitization: market overview, background and evolution. In: Barrieu, P., Albertini, L. (eds.) The Handbook of Insurance-Linked Securities, 1st edn., pp. 9-18. Wiley, West Sussex (2009). Chap. 2

Standard, Poor's: Methodology and assumptions for rating natural catastrophe bonds. Report (2009)

Swiss Re: Securitization: new opportunities for insurers and investors. Sigma 7/2006, Zurich (2006)

Swiss Re: The role of indices in transferring insurance risk to the capital markets. Sigma 4/2009, Zurich (2009)

Towers Watson: Catastrophe bonds evolve to address credit risk issues. Report (2010)

Vasicek, O.: An equilibrium characterization of the term structure. J. Financ. Econ. 5(2), 177-188 (1977)

Vaugirard, V.E.: Pricing catastrophe bonds by an arbitrage approach. Q. Rev. Econ. Finance 43(1), 119132 (2003a)

Vaugirard, V.E.: Valuing catastrophe bonds by Monte Carlo simulations. Appl. Math. Finance 10(1), 75-90 (2003b)

Vaugirard, V.E.: A canonical first passage time model to pricing nature-linked bonds. Econ. Bull. 7(2), 1-7 (2004)

White, H.: A heteroskedasticity-consistent covariance matrix estimator and a direct test for heteroskedasticity. Econometrica 48(4), 817-838 (1980)

Wooldridge, J.M.: Introductory Econometrics. A Modern Approach, 4th edn. South-Western, Mason (2008)

Wu, Y.-C., Chung, S.-L.: Catastrophe risk management with counterparty risk using alternative instruments. Insur. Math. Econ. 47(2), 234-245 (2010)

Young, V.R.: Pricing in an incomplete market with an affine term structure. Math. Finance 14(3), 359-381 (2004)

Zhu, W.: Ambiguity aversion and an intertemporal equilibrium model of catastrophe-linked securities pricing. Insur. Math. Econ. 49(1), 38-46 (2011)

Zimbidis, A.A., Frangos, N.E., Pantelous, A.A.: Modeling earthquake risk via extreme value theory and pricing the respective catastrophe bonds. ASTIN Bull. 37(1), 163-184 (2007) 